\title{
Distribution of plantar pressure and body posture in spastic cerebral palsy
}

\author{
Claudia Morais Trevisan', Giselle de Camargo Oliveira', Juliana Alves Souza', Eduardo Cabral da Silva'
}

\begin{abstract}
Introduction: Cerebral palsy (CP) describes a group of permanent disorders of movement and posture due to a non-progressive disorder that occurs during the fetal or infant brain, may contribute to limitations in the functionality. Objective: To investigate the distribution of plantar pressures and the body posture in spastic CP. Methods: A descriptive case series study conducted at the Sector Outpatient Pediatric Rehabilitation Neurofunctional the University Hospital of Santa Maria - RS. Seven children with spastic CP, level I and II were included in the Gross Motor Function Classification System. Plantar pressures were analyzed using a baropodometry system - Footwork - and the type of the foot was calculated by index-ChipauxSmirak. Postural alignment was assessed subjectively in anteroposterior and lateral views. Data were analyzed using descriptive statistics. Results: The asymmetric distribution of plantar pressures were evidenced in hemiparetic, diparetic and quadriparetics CP evaluated and the prevalence of flat foot occurred. The most frequent postural changes were the forward and head tilt, elevation, tilt and protrusion of shoulder, cervical and lumbar lordosis, thoracic kyphosis, the anterversion and unevenness of the hip and pronation of the feet. Conclusions: In this group of children plantar pressures and posture proved to be altered. These findings may influence the prognosis of deformities and functional rehabilitation outcomes. The use of photometry and baropodometry may assist in a more efficient therapeutic intervention.
\end{abstract}

Keywords: Cerebral Palsy; Spastic; Postural balance; Foot Deformities.

\section{INTRODUCTION}

Cerebral palsy (CP) describes a group of permanent disorders of movement and posture assigned to a non-progressive disorder, that occurs during the fetal or infant brain development, which may contribute to limitations in the functionality profile. ${ }^{(1)}$ The prevalence of the pathology in developed countries ranges from 1.5 to 5.9/1000 live births; in developing countries it is estimated that the incidence is 7:1000 live births. This difference between the two groups of countries may be attributed to poor prenatal care and primary care to pregnant women. ${ }^{(2)}$

CP motor disorders are frequently accompanied by, sensory, perceptual, cognitive, communication and behavioral disorders, epilepsy and secondary musculoskeletal problems. The complexity of this syndrome allows several classifications, being defined according to the anatomical site of the cerebral lesion (cerebral cortex, pyramidal tract, extrapyramidal or cerebellum); clinical signs and symptoms (spastic, dystonic and choreo-athetotic or ataxic forms); the topographic involvement of the extremities (diplegia, quadriplegia, or hemiplegia); the period of injury (prepartum, intrapartum and postneonatal) and also classified as the muscle tone (hypotonic, isotonic or hypertonic). ${ }^{(3)}$

Spastic form is prevalent in children whose $\mathrm{CP}$ is consequent to preterm birth, while dyskinetic and ataxic forms are common in children born at term. ${ }^{(4)}$ In the spastic CP the high tone is caused by injury to the pyramidal system and is characterized by increased muscle tension when it is passively extended. ${ }^{(4.2)}$ Adversely, the motor development is affected, leading to posture and abnormal movement patterns.

Commonly, the child with spastic CP evolves with changes in joint range of motion and contractures of the hip, knee, ankle and foot muscles, which may contribute to an atypical pattern in standing posture and difficulty in voluntary movement. This atypical postural alignment may also be expressed by a change in body position with respect to gravity and the holder. ${ }^{(5)}$ It is known that a balanced distribution of weight between the two legs, in the standing position, provides an optimum biomechanical stability, facilitating the voluntary movement and preventing muscle fatigue. However, postural deficit in $\mathrm{CP}$, which involves tone and abnormal reflex activity, increasing of co-contraction of agonists and antagonists, decrease of trunk 
muscle activation and incoordination, may affect the ability to maintain standing posture and, consequently, the symmetry in the distribution of weight in the sole of the feet. ${ }^{(6,7)}$ Recent studies have shown that children with hemiparetic CP may or may not burden the lower limb affected in bipedalism and that the changes in body posture are also related to this behavior. ${ }^{(5-7)}$

Regarding to these aspects, the objective of this study was to investigate the distribution of plantar pressures and body posture of children with spastic CP treated at the Pediatric Neurofunctional Ambulatory Rehabilitation Sector of the Physiotherapy Service of the University Hospital of the Federal University of Santa Maria.

\section{METHOD}

Descriptive study of the type series of cases, developed in the Ambulatory Neurofunctional Pediatric Rehabilitation Sector of the University Hospital of the Federal University of Santa Maria. Approved by the Ethics and Research Committee of the Federal University of Santa Maria, protocol $\mathrm{n}$ o 236.697. It was included in the study, after the consent of the responsible, children attended at the outpatient clinic, with spastic CP diagnostic classified in levels I and II in the Gross Motor Function Classification System (GMFCS). ${ }^{(8)}$ GMFCS has been widely accepted in clinical practice and in research, in which is based on the movement initiated voluntarily, with emphasis on sitting, transfers and mobility, setting the child or adolescent with CP in five levels of motor function (ranging from I, which includes the presence of minimal or no impairment with respect to community mobility, until the fifth, when there is total dependence requiring assistance for mobility). ${ }^{(2,4)}$

In baropodometric evaluation was used a computerized platform that captures the pressures developed in different plantar points in the standing position. ${ }^{(9)}$ The electronic baropodometry Footwork system with active area of $400 \times 400 \mathrm{~mm}$, dimensions $645 \times 520 \times 25 \mathrm{~mm}$, with 704 calibrated capacitive sensors, frequency $150 \mathrm{~Hz}$, maximum pressure per capacitor $100 \mathrm{~N} / \mathrm{cm}^{2}$, analog converter 16 bits and with the capacitor measurement of $7.62 \times 7.62 \mathrm{~mm}$ was used (Figure 1). The calibration of equipment was performed by

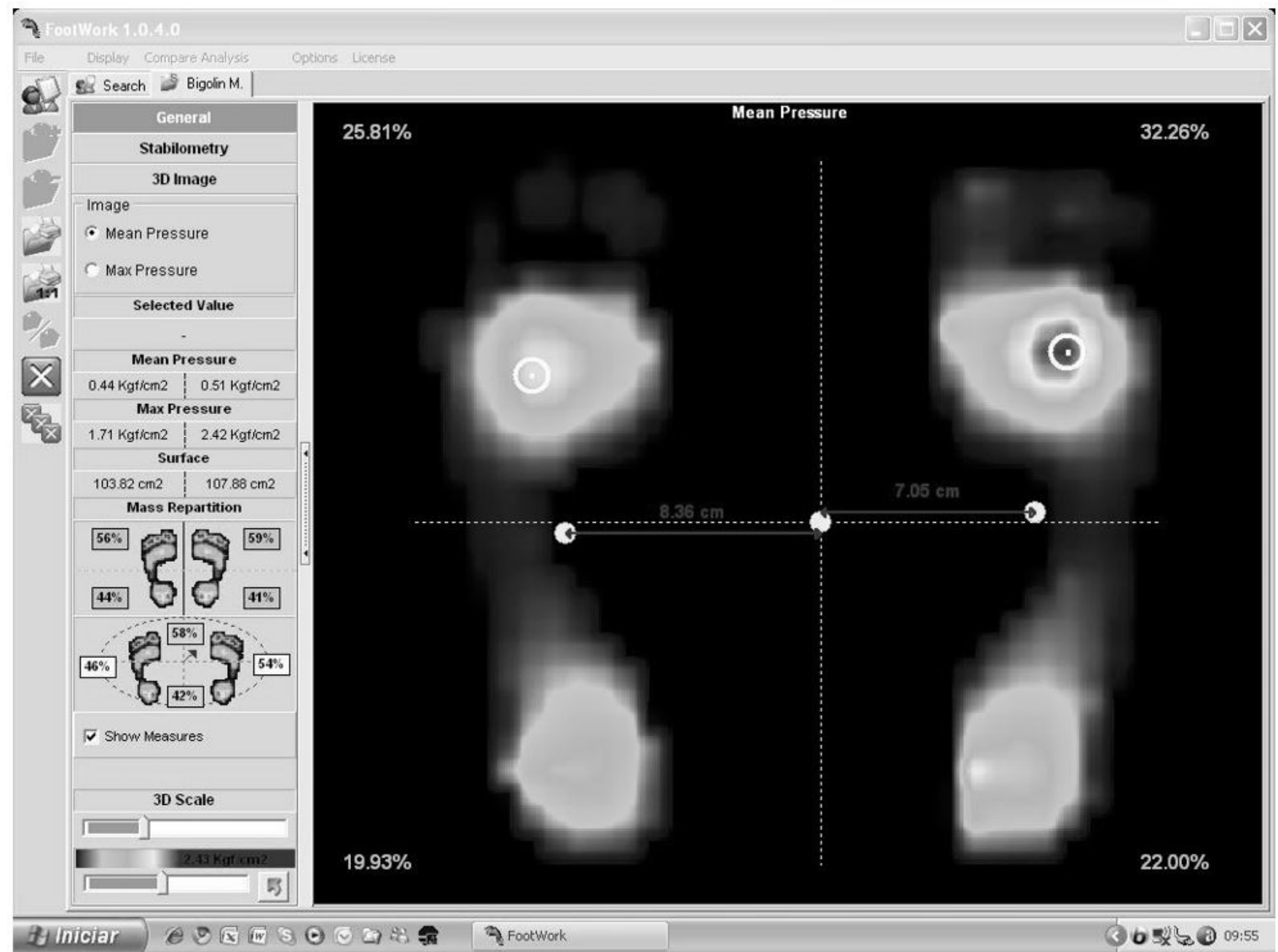

Figure 1. Baropodometric rating (Fotwork Software). 
the weight, height and number of the child's shoes, measured at the time of evaluation (Leader-LD1050 scale). During the examination, the child remained standing barefoot, with her feet parallel, her arms loose along her body, and her gaze fixed at a point in the eye line for a minimum of nine seconds. This time was established because they are children with difficulty to remain in static posture for a long time. ${ }^{(10)}$ Each record was repeated three times, for greater reliability, ${ }^{(11)}$ with an interval of 10 seconds and it was considered the average of the three collections for analysis.

The baropodometric parameters evaluated were related to the distribution of the plantar pressures in the anterior and posterior direction, i.e. the forefoot and the backfoot; and the right and the left. It was considered as normal standard 57-60\% of body weight for the heels, $40-43 \%$ for the forefeet, $50 \%$ to the right lower limb and 50\% for the left. ${ }^{(12)}$ Characterizing body antepulsion or retropulsion and right or left body laterality when values exceeded these limits.

The foot type was calculated by the Chipaux-Smirak index (CSI), in order to quantitatively evaluate the plantar arches. For this purpose, two straight lines, obtained from baropodometric registry, were drawn in the right and left plantar impression: a tangent to the most medial points in the region of the heads of the first metatarsals and the calcaneus, and another tangent to the most lateral point of the head of the fifth metatarsals and calcaneus. Following, a straight line connecting the most medial point and the most lateral point in the region of the metatarsal heads it was marked, delimiting the largest printing width in this region ("a" segment). It drew up another segment parallel to this, in the smallest width of the foot in the arch plantar medial longitudinal or midfoot (" $b$ " segment). Both segments were measured ( $a$ and $b$ ) and the last divided by the first, obtaining a percentage (Figure 2). The higher the CSI, flatter is the foot. Five categories are described for the classification of the medial longitudinal arch according to this index: 0\% - raised arch foot (cavus); 0.1-29.9\% - normal morphologically arch foot; 30-39.9\% - intermediate foot (flat grade I); $40-44.9 \%$ lower arch foot (flat grade II); $45 \%$ or greater - planus foot (flat grade III). ${ }^{(13)}$

Postural alignment was evaluated by photometry, subjectively, according to Kendall protocol, MacCreary and Provance, ${ }^{(14)}$ in the anteroposterior and lateral right and left views (head, shoulder, shoulder blade, hip, knee, foot, cervical spine, thoracic and lumbar). In order to carry out the photographs, the subjects were positioned in orthostatism (parallel feet, upper limbs relaxed along the body and looking at the horizon) in front of a posturograph, in a place that did not have ground difference and, with the aid of a plumb line. The subjects wore bathing suits, without shoes and socks, or any type of accessories (Figure 3). A digital camera (Coolpix L120 Nikon 921K-dot 14.1 MP LCD 2.4) was positioned 3 meters from the posturograph and vertically $1.50 \mathrm{~cm}$ above the floor, on a tripod. Each photographic record was repeated three times for each position, it was considered the best of the three photos for analysis. ${ }^{(12)}$

All evaluations were performed by experienced examiners, who did not participate in the physiotherapeutic care of children; in a reserved place, preserving privacy. Before the collections, the caregiver and the children were instructed on the procedures that would be performed, and their assistance was requested when the child was impatient or not very collaborative.

The data collected were analyzed using descriptive statistics.

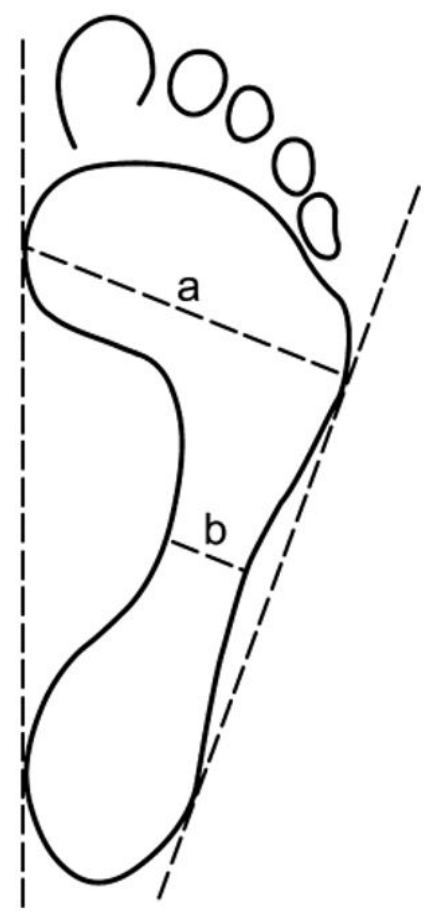

Figure 2. Foot type rating - Chippaux-Smirak Index (CSI = b/a, as $\boldsymbol{b}$ a smaller width in the longitudinal arch region and $\boldsymbol{a}$, the largest width in the region of the metatarsal heads).

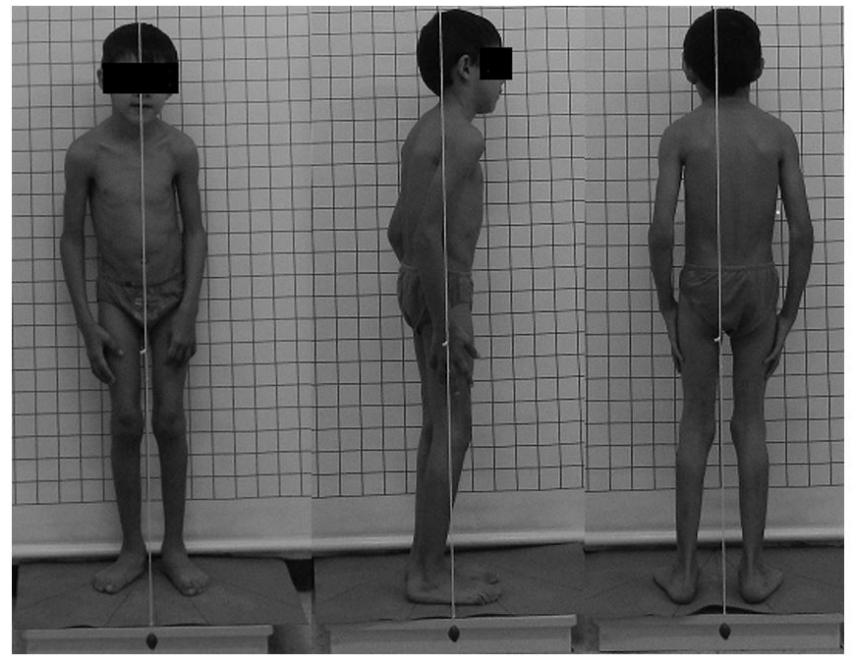

Figure 3. Evaluation of body posture. 


\section{RESULTS}

50 children with movement disorders attending the physiotherapy outpatient clinic, 12 had a CP diagnosis. Of these, 7 corresponded to the inclusion criteria of the research. The characteristics of the study group are shown in Table 1. The distribution of bipedalism (static) plantar pressures is shown in Table 2.

According to the classification of Chipaux Smirak index ${ }^{(13)}$ of the type of foot, four children had both feet flat grade III (two hemiparetic, one diparetic a quadriparetic) a diparetic female presented the two arched feet and two children asymmetric feet (One quadriparetic and one hemiparetic on the right).

Regarding to the results obtained in the postural evaluation in the lateral view, we highlight the anterioration of the head and shoulders in all children. The three hemiparetic CPs and the two diparetics presented cervical hyperlordosis, dorsal hyperciphosis and lumbar hyperlordosis. In the diparetics, the pelvis was anterior tilt with flexed knees (child 4) and hyperextended (child 5). All hemiparetics presented anti tilt pelvic with hyperextended knees, the two quadripartics presented cervical hyperlordosis, thoracic hypercaphysis and lumbar rectification with posterior tilt pelvis and flexed knees.

In anterior-posterior views, head tilt and rotation, elevation, tilt and shoulder protrusion with scapula abduction, were observed in all children. The three hemiparetics had oblique pelvis, valgus knees (children 2 and 3), and varus (child 1) with pronounced right and left feet pronated (children 1 and 3 ) and pronated feet (child 2). The two dipyratics presented pelvic obliquity, valgus knees and pronated feet. In both quadripartics, the pelvis was oblique, the knees in internal rotation and pronated feet (child 7) with the left foot supinated and the right pronated (child 6).

\section{DISCUSSION}

The CP presents a complex of symptoms which manifests as a change in movement that can change the presentation, growth and development of the individual. These changes along with abnormalities of tone, balance, movement and reflex activity can lead to a pattern of improper body posture. ${ }^{(5)}$

The ability to keep aligned the body segments and the projection of the center of mass within the support base limits are prerequisites for maintaining body balance. ${ }^{(15)}$ The static equilibrium of children with $\mathrm{CP}$ is characterized by increased postural oscillation, reduction in the area of stability and change in pressure center position, with a reduction in the percentage of body weight transferred to the paretic limb. ${ }^{(16)}$ In this study changes were observed in the plantar pressures and in body posture in all children assessed, independent of spastic CP topography. The asymmetric distribution of the plantar pressures was evidenced in the

Table 1: Descriptive data of the study group.

\begin{tabular}{|c|c|c|c|c|c|c|c|}
\hline CP & Topographic & GMFCS & & Age & Height & Weight & Shoes \\
\hline Spatic & Distribution & Level & & (years) & $(\mathrm{cm})$ & $(\mathrm{kg})$ & Number \\
\hline 1 & Hemiparesis L & ॥ & $M$ & 3 & 105 & 30 & 19 \\
\hline 2 & Hemiparesis $\mathrm{R}$ & 1 & $\mathrm{M}$ & 3 & 95 & 22 & 14 \\
\hline 3 & Hemiparesis $\mathrm{R}$ & I & $\mathrm{F}$ & 5 & 106 & 25 & 22 \\
\hline 4 & Diparesia & ॥ & $\mathrm{F}$ & 3 & 97 & 23 & 14 \\
\hline 5 & Diparesia & 1 & M & 6 & 128 & 31 & 31 \\
\hline 6 & Quadriparesia & ॥ & $\mathrm{F}$ & 7 & 118 & 26 & 23 \\
\hline 7 & Quadriparesia & ॥ & $M$ & 8 & 119 & 31 & 21 \\
\hline
\end{tabular}

CP: cerebral palsy; GMFCS: Gross Motor Function Classification System; F: female; M: male; R: right; L: left; cm: contimeters; kg: kilograms.

Table 2 - Distribution of plantar pressures in the study group.

\begin{tabular}{|c|c|c|c|c|c|}
\hline \multirow{2}{*}{\multicolumn{2}{|c|}{ CP - Topography }} & \multicolumn{4}{|c|}{ Plantar Pressures } \\
\hline & & Anterior (\%) & Posterior(\%) & Lateral R(\%) & Lateral L(\%) \\
\hline \multirow{3}{*}{ Hemiparesis ( $n=3$ ) } & $E$ & 58.00 & 42.00 & 56.00 & 44.00 \\
\hline & $\mathrm{D}$ & 35.00 & 65.00 & 2900 & 71.00 \\
\hline & D & 38.00 & 62.00 & 47.00 & 53.00 \\
\hline \multirow{2}{*}{ Diparesis $(n=2)$} & & 52.00 & 48.00 & 47.00 & 53.00 \\
\hline & & 30.00 & 70.00 & 45.00 & 55.00 \\
\hline \multirow{2}{*}{ Quadriparesis $(n=2)$} & & 53.00 & 47.00 & 70.00 & 30.00 \\
\hline & & 51.00 & 49.00 & 63.00 & 37.00 \\
\hline
\end{tabular}

$\mathrm{CP}$ : cerebral palsy; R: right; L: left; $n=$ number of children. 
hemiparetic, diparetic and quadriparetic CPs evaluated, being the flat foot predominant. Head and shoulder anteriority, cervical and lumbar hyperlordosis, thoracic hyperkinesis and pelvic anterversion were the most observed postural changes in the lateral view. In the anteroposterior view, the head inclination, elevation, inclination and protrusion of the shoulders, abduction of the shoulder blades, pelvic obliquity and pronated feet were also frequent. Studies show abnormal patterns of posture or by reducing the range of motion in relevant joints in cases of diparesis, triparesia and quadriparesia or compensation due to weakness in the case of monoparesis and hemiparesis ${ }^{(5,6,17)}$ according to our findings.

The CP spastic hemiparetic, usually shows a pattern of upper limb flexion, lateral flexion of head and trunk to the affected side, along with lower limb hyperextension, ${ }^{(18)}$ this pattern was observed in children with hemiparesis in this study. Asymmetries in the distribution of plantar pressures were also observed since the hemiparetic CP on the left presented a pattern of body prepulsion and right lateral laterality; while the two hemiparetics on the right were in retropulsion and the weight placed more on the left lower limb. Such findings justify the chain of postural compensations, with contralateral lower limb overload. For Domagalska-Szopa and Szopa, ${ }^{(6)}$ hemiparetic children with asymmetrical body discharge tend to present a scapular rotation and a pelvic obliquity. On the other hand, when they present symmetrical discharge of weight the compensation appears as scoliosis.

The cause of scoliosis in CP is not entirely clear, but the combination of factors such as muscle weakness, trunk imbalance, asymmetry of the spinal muscles of the paraspinal and intercostal muscles may contribute to the evolution of the scoliosis. The incidence varies from 6 to 100\%, with the related progression in type engagement (Quadriparesis), poor functional status (GMFC levels I and IV), the location of the curve (thoracolumbar). ${ }^{(17)}$ The risk of developing scoliosis increases with level and GMFCS and age, and in most children scoliosis is diagnosed after the age of eight. Children GMFCS IV and V levels have $50 \%$ chance in developing moderate to severe scoliosis at 18 , while children with levels I and II have decreased risk. ${ }^{(19)}$ Considering these aspects, although all the children in this study present slope of the shoulders and unevenness of the pelvis, hardly they will evolve from bad to severe scoliosis, since the level GMFCS presented by them do not show great commitment. Robdy-Bousquetet al. ${ }^{(20)}$ in the investigation of postural changes of young adults with $\mathrm{CP}$, found that those with GMFCS I and II levels the tilt of the head and trunk were the most common changes.

Spastic diparesis is characterized by more intense involvement of the lower limbs, which usually, have an increased adduction and internal rotation of the hips, excessive knee flexion associated with valgus and equinovarus. ${ }^{(21,22)}$ The two children spastic diparéticas evaluated in this study presented valgus of knees and feet pronated, one of them with flat feet and the other cavus feet. The other body segments were also misaligned as well as the distribution of the weight on the soles of the feet, with left laterality in both, one child in forearm and another in body retropulsion. These biomechanical changes, secondary to spasticity and muscle weakness, may result in impaired static and dynamic balance. According to Rojas et al, (23) the diparetic have a control ability of the reduced postural balance and stability lower standing compared to hemiparesis CP.

Spastic quadriparetics CPs also showed compromised overall body posture, with increased cervical and dorsal curvature and lumbar rectification, internal rotation and semi-flexion of the knees; about the two children, one had flat feet and the other flat feet and cavus feet. There was an imbalance in the distribution of the weight on the soles of the feet, with forefoot and laterality on the right, making it difficult to stand upright. The large number of postural alterations and baropodometry were expected in these children, since spastic quadriparesis is the most severe form of $C P$, usually evidenced by an overall alteration of muscle tone, a decrease in spontaneous motor and joint mobility. According to Bobath ${ }^{(18)}$ and Segura et al. ${ }^{(24)}$ in spastic quadriparesia, features as lateral flexion of the neck, adduction and internal rotation of the shoulder, spine asymmetry, extension and hip internal rotation are evidenced, and bipedalism occurs at the tips of feet with the rigid legs in extension or semiflexion, adduced and rotated internally, as identified in the children evaluated in this study.

The deformity in flat feet was the most frequent in the children who participated in the research. The flat foot on the CP is by shortening of the achilles tendon or a decreased weight bearing, when, for example, the child takes time to walk, which usually is associated with valgus of the foot and knee. ${ }^{(25)}$ agreeing with our findings, Costa et al., ${ }^{(10)}$ using the baropodometry system, found that the flat foot was the most common in the evaluated 16 CPs aged 6 to 15 years. It is important to remember that the age variation in our study was shorter (three to eight years) and that up to three years of age, the child's foot has a greater degree of mobility than the adult foot, as a consequence of a greater peculiar ligament elasticity in the early life. This fact, allied to support base extension of the child at the beginning of the march, facilitates the fall of calcaneal in valgus. ${ }^{(25)}$ According Sees and Miller ${ }^{(26)}$ the deformities are common in the feet of children with $\mathrm{CP}$, being the natural history of this variable deformity and unpredictable before the age of five years.

As a limitation of the study, we can cite the heterogeneity of the evaluated children, the difference between ages and the biological individuality of each one. Therefore, new studies are suggested, with larger samples and also children classified according to CP topography, age and degree of motor impairment. In addition, studies using these assessment tools, since baropodometry is an important tool to understand the postural influences on the feet and the influence of the feet 
on the posture ${ }^{(9.12)}$, while the evaluation of body posture is an initial step in the planning and monitoring of physiotherapeutic treatment. It is believed that by deepening knowledge in these aspects, it may bring new clarifications in order to help and improve new treatments for children with $\mathrm{CP}$.

\section{CONCLUSION}

Based on the results, it is possible to conclude that children with $\mathrm{CP}$ in this study group, whether hemiparetic, dipartic or quadripartic, present changes in both plantar pressures and body posture. These findings may influence the prognosis of deformities and functional rehabilitation results, since the position is directly linked to the execution of tasks and the quality of life of these children. In addition, these evaluations provide parameters for the preparation of an adequate treatment plan that allows not only the prevention of deformities, but also the postural restructuring, assisting in a more efficient therapeutic intervention.

\section{AUTHOR'S CONTRIBUTION}

ECS, JAS and CMT: design and development (from the initial idea to the research and the hypothesis of study); JAS and CMT: supervision (responsible for the organization and execution of the project and writing of the manuscript); ECS and GCO: literature research (participated in the search and analysis of bibliographic review articles); ECS, GCO and JAS: collection and processing of data (responsible for patient selection and evaluation and data organization); ECS, GCO, JAS and CMT: analysis, interpretation and writing (responsible for statistical analysis, evaluation and presentation of results found, discussion, besides substantial writing of the manuscript); JAS and CMT: critical review (responsible for reviewing the intellectual content of the manuscript before the final presentation).

\section{CONFLICTS OF INTEREST}

The author(s) declare that they have no competing interests.

\section{REFERENCES}

1. Rosebaum P, Paneth N, Leviton A, Goldstein M, Bax M. A report: The definition and classification of cerebral palsy. Developmental Medicine and Child Neurology. 2007;49:(2):8-14.

2. Diretriz Brasileira de Atenção à Pessoa com Paralisia Cerebral. Ministério da Saúde. Secretaria de Atenção à Saúde. Departamento de Ações Programáticas Estratégicas. - Brasília: Ministério da Saúde; 2013.

3. Colver A, Fairhurst C, Pharoah POD. Cerebral palsy. Lancet. 2014;383: 1240-49.

4. O'Shea MT. Diagnosis, Treatment, and Prevention of Cerebral Palsy in Near-Term/Term Infants. ClinObstet Gynecol. 2008;51(4):816-828.

5. Domagalska ME, Szopa AJ, Lembert DT. A descriptive analysis of abnormal postural patterns in children with hemiplegic cerebral palsy. Medical Science Monitor. 2011;17(2):110-116.

6. Domagalska-Szopa M, Szopa A. Body Posture Asymmetry Differences between Children withMild Scoliosis and Children with Unilateral Cerebral Palsy. BioMed Research International. 2013; disponível em http://dx.doi. org/10.1155/2013/462094
7. Domagalska-Spoza M, Spoza A. Postural pattern recognition in children with unilateral cerebral palsy. Therapeutics and Clinical Risk Management. 2014;10:113-120.

8. Palisano RJ, Rosenbaum P, Bartlett D, Livingston, $\mathrm{MH}$. Content validity of the expanded and revised Gross Motor Function Classification System. Developmental Medicine \&ChildNeurology. 2008;50:744-750.

9. Rosario JL. A review of the utilization of baropodometry in postural assessment. J Bodyw Mov Ther. 2014 Apr;18(2):215-9.

10. Costa TDA da, Carvalho SMR de, Braccialli LMP. Análise do equilíbrio estático e de deformidades nos pés de crianças com paralisia cerebral. Fisioter Pesq. 2011;18(2):127-32.

11. Guerney JK, Kersting UG, Rosenbaum D. Between-day reliability of repeated plantar pressure distribution measurements in a normal population. Gait and Posture. 2008;27:706-709.

12. Souza JA, Pasinato F, Corrêa ECR, Silva AMT da. Global body posture and plantar pressure distribution in individuals with and without temporomandibular disorder: a preliminary study. Journal of Manipulative and Physiological Therapeutics. 2014;37(6):407-414.

13. Onodera NA, Sacco ICN, Morioka EH, Souza OS, Sá MR de, Amadio CA. What is the best method for child longitudinal plantar arch assessment and when does arch maturation occur? The Foot. 2008;142-149.

14. KendallF, McCreary EK, Provance PG. Músculos provas e funções. São Paulo: Manole; 2007.

15. Pavão SL, Santos NA dos, Woollacott MH, Rocha NACF. Assessment of postural control in children with cerebral palsy: A review. Research in Developmental Disabilities. 2013;34:1367-75.

16. Mello MM, Ries LGK. Confiabilidade de medidas de estabilidade postural de crianças com hemiparesia EFDeportes.com, Revista Digital. Buenos Aires, 2010;15(150). http://www.efdeportes.com/

17. Rutz E, Brunner, R. Management of spinal deformity in cerebral palsy: conservative treatment. J Child Orthop. 2013;7:415-18.

18. Bobath B, Bobath K. Desenvolvimento motor nos diferentes tipos de paralisia cerebral. São Paulo: Manole; 1989.

19. Persson-Bunke $M$, Hägglund $G$, Lauge-Pedersen $H$, Wagner $P$, Westbom L. Scoliosis in a Total Population of Children With Cerebral Palsy. SPINE. 2012;37(12):708-13.

20. Robdy-Bousquet E, Czuba T, Hagglund G, Westbom L. Postural asymmetries in young adults with cerebral palsy. Dev Med Child Neurol. 2013;55(11):1009-15.

21. Rotta NT. Paralisia cerebral: novas perspectivas terapêuticas. J Pediat. 2002;78(Supl 1):48-54.

22. Hägglund $G$, Lauge-Pedersen $H$, Wagner $P$. Characteristics of children with hip displacement in cerebral palsy. BMC Musculoskelet Disor. 2007;8(1):101-16.

23. Rojas VG, Rebolledo GM, Munoz EG, Cortés NI, Gaete CB, Delgado CM. Differences in standing balance between pacientes with diplegic and hemiplegic cerebral palsy. Neural Regen Res. 2013;8(26):2478-2483.

24. Segura DCA, Crespão DL, Darlot M, Beledel AS, Picinini JAS. Análise do tratamento da espasticidade através da fisioterapia e farmacologia - um estudo de caso. Arq Ciênc Saúde Unipar. 2007;11:217-24.

25. Cargnin APM, Mazzitelli C. Proposta de tratamento fisioterapêutico para crianças portadoras de paralisia cerebral espástica, com ênfase nas alterações musculoesqueléticas. Revista Neurociências. 2003;11(1):34-39.

26. Sees JP, Miller F. Overview of foot deformity management in children with cerebral palsy. J Child Orthop. 2013;7(5):373-7. 